REVISTA X, Curitiba, volume 12, n.2,p.289-305,2017

\title{
BREVES NOTAS SOBRE A LEITURA EM PLE: ASPECTOS FONÉTICOS
}

\author{
Brief Notes on Reading in Portuguese as a Foreign Language: Phonetic Aspects
}

\author{
Diocleciano NHATUVE ${ }^{1}$
}

\begin{abstract}
RESUMO: O processo de leitura desempenha um papel preponderante na aquisição de qualquer língua estrangeira através do ensino-aprendizagem. Neste artigo, debruçase sobre os aspetos fonéticos no processo de leitura em português por alunos cujas línguas materna e segunda são respetivamente o shona e o inglês. O estudo revelou os seguintes aspetos fonénicos: (1) a tendência para a aspiração das consoantes oclusivas [t], [p] e [k] na primeira posição da palavra ou quando combinadas com o grafema $<\mathrm{r}>$; (2) a ocorrência do fenômeno de epêntese junto da nasal bilabial [m] na posição final da palavra; (3) dificuldades na pronúncia do ditongo nasal [ãw] e da lateral $[\Lambda]$, dados que, até certo ponto, se distancia dos que foram revelados por Mateus (s/d) e outros linguistas sobre outros aprendentes do PLE. Sublinha-se, entretanto, que estes aspetos se devem à influência das duas línguas em que os alunos são proficientes, representando, com efeito, o processo de construção das respetivas interlínguas. Por isso, os professores devem estar atentos ao processo e munir os seus alunos de pronúncia adequada para que, efetivamente, eles se beneficiem do exercício de leitura para aprender PLE.
\end{abstract}

PALAVRAS-CHAVE: Leitura, Português Língua Estrangeira, AspeCtos Fonéticos, Interlíngua.

ABSTRACT: The process of reading plays a very important role in the teaching and learning process of the acquisition of foreign languages. In this paper we discuss phonetic aspects of the reading activities in the Portuguese Foreign Language class by students whose mother tongue and second language are, respectively, Shona and English. The following tendencies, with regard to phonetic aspects were identified: (1) students tend to give the aspirated feature to the plosive consonants $[\mathrm{t}],[\mathrm{p}]$ and $[\mathrm{k}]$ in the first position of the word or when they are combined with $\langle\mathrm{r}\rangle$; (2) the phenomenon of epenthesis occurs when the word in Portuguese ends by [m]; (3) students face difficulties to pronounce the nasal Portuguese diphthong [ãw] and the lateral $[K]$, data somehow different from that revealed by Mateus, $(\mathrm{s} / \mathrm{d})$ and others linguists regarding other learners of the Portuguese Foreign Language. It is highlighted that all these aspects occur due to the influence of the two languages in which students are proficient and they represent the construction of students' interlanguage. Hence, lecturers need to be aware of the process, and lead students to good pronunciation, so that they can effectively benefit from the exercise of reading when learning Portuguese.

\footnotetext{
${ }^{1}$ Leitor de Língua Portuguesa na Universidade do Zimbabwe ; Doutorando em Língua Portuguesa: Investigação e Ensino - Universidade de Coimbra. djrnhatuve@gmail.com
} 
KEY-WORDS: Reading; Portuguese Foreign Language; Phonetic aspects; Interlanguage.

\section{INTRODUÇÃO}

Estudos na área de ensino-aprendizagem de línguas estrangeiras (LE) têm demonstrado a pertinência de leitura, como uma habilidade e uma estratégia que catapultam a aprendizagem, tornando o aluno ativo e independente do professor muito cedo. No entanto, o processo de ensino-aprendizagem sujeita-se ao contacto entre as línguas já desenvolvidas pelo aluno e o novo idioma, dando lugar às tradicionais interferências sintáticas, fonéticas, etc.

Considerando que os aprendentes de português língua estrangeira (PLE) têm perfis linguísticos diferentes, prevê-se a diferença entre os aspetos resultante do contacto do novo código com as línguas dos alunos. Aliás, baseando-se na ideia behaviorista de desenvolvimento humano, os diferentes contextos de ensinoaprendizagem de PLE têm diferentes influências no desenvolvimento das competências em português. Neste sentido, tendo em conta que alguns autores (MATEUS, s/d; ESPIGA, 2001; FERNANDES, 2001) já revelaram alguns aspetos fonéticos que sobressaem no contacto entre o português e outras línguas, formula-se uma questão sobre quais os aspetos fonéticos salientes no encontro entre o PLE e o shona e o inglês.

Desta feita, intenta-se com este estudo descrever os aspetos fonéticos particulares aos falantes das duas línguas quando usam a língua portuguesa e as respetivas causas. A motivação deste estudo resulta do fato de se verificar que os aspetos fonéticos quer na leitura quer na fala têm muitas implicações no processo de aquisição de PLE: primeiro, tornam difícil a perceção das leituras; segundo, comprometem as produções escritas; enfim, a aprendizagem do português. A identificação dos aspetos e das causas particulares permitirá a tomada de estratégias úteis para o ensino de PLE.

Para tal, o estudo consiste na análise das leituras aos pares feitas por 29 alunos aprendentes de PLE na Universidade do Zimbabwe, com idades entre os 19 e 30 anos, os quais falam shona e inglês. As leituras foram gravadas durante uma aula de leitura 
e, para efeitos de análise, foram identificados os contextos e as palavras em que se revelam muitas dificuldades. Os elementos identificados como sendo pronunciados de maneira desviante foram transcritos foneticamente e contrastados com as realizações previstas no $\mathrm{PE}^{2}$.

\section{REVISÃO DA LITERATURA}

A aprendizagem das LEs está, hoje em dia, na moda. Com efeito, há cada vez mais pessoas a decidirem aprender PLE em todo o mundo. Como os aprendentes de PLE, sobretudo jovens e adultos, têm o conhecimento das suas línguas maternas (LM) e de uma língua segunda (L2) (especialmente no contexto africano) que tendem a estar presentes nos diferentes níveis e aspetos de aprendizagem de LE (NGUNGA, s/d, p. 8 e BLEY-VROMAN, 1990, p. 15), vários aspetos (fonéticos, sintáticos, morfológicos, semânticos) relacionados com a interferência quer da LM quer da L2 (KRASHEN, 1981, P. 64-65) ganham vulto como resultado do encontro dos diferentes sistemas linguísticos.

Neste contexto, as dificuldades e desvios dos aprendentes de PLE ou de qualquer LE podem ter explicação no âmbito da teoria behaviorista de Watson e Skinner, dois psicólogos americanos, formados respetivamente nas Universidades de Chicago e Harvard e que viriam a influenciar os estudos de psicologia humana durante muitos anos nos Estados Unidos e não só. Fundado por Watson em 1913, num artigo "Psicologia vista por um behaviorista" e desenvolvido significativamente por Skinner na sua obra "The Behaviour of Organisms" em 1938, o behaviourismo defende o comportamento humano como fruto de estímulos externos (BOCK, FURTADO E TEXEIRA, $1999^{13}$, p. 57-74).

A teoria Behaviourista, no âmbito da aprendizagem de uma LE, sugere o desenvolvimento das competências linguística e comunicativa através e como resultado do input que o meio social e de convivência proporcionar ao indivíduo como experiência. Por outras palavras, preconiza que a performance dos aprendentes de PLE, por exemplo, está condicionada pelo contexto linguístico em que se encontram inseridos, isto é, quanto vasto e melhor for a quantidade e a qualidade do input

\footnotetext{
${ }^{2}$ Português europeu
} 
externo, altos níveis de aprendizagem e proficiência serão atingidos pelos aprendentes. No caso concreto da destreza na leitura em PLE, esta irá ser condicionada quer pelo contexto sociofamiliar (a frequência com que este contexto proporciona situações de leitura em PLE) quer pelo contexto escolar, sendo crucial o ambiente da sala, o número de vezes que cada aluno tem de ouvir e fazer leituras em português, a criação de motivação necessária para despertar no aluno o gosto e a pertinência da leitura.

No cômputo geral, a leitura é uma competência crucial que se deve desenvolver para os alunos se tornarem fluentes em qualquer língua (DUARTE, 2000, p. 55). Ela implica, em todos os casos, "a conversão do código escrito em código oral (verbalizável), pressupondo a compreensão ou, pelo menos, o reconhecimento do material impresso" (FESTAS, MARTINS E LEITÃO, 2007, p. 2). É importante fazer referência neste trabalho ao modelo psicolinguístico de leitura que pressupõe duas vias para efetivar a leitura: a via fonológica - que consiste na conversão de grafemas em fones e permite a leitura de "palavras desconhecidas e pseudopalavras" até ao leitor menos proficiente - e a via lexical - que consiste no recurso ao dicionário mental ou léxico mental onde estão representadas todas as palavras já aprendidas e reconhecidas (op. cit. P. 3-4).

Numa perspetiva de uma teoria de leitura, Gibbons (2002) considera que, no exercício da leitura, os indivíduos necessitam de um conjunto de ferramentas linguísticas. Dentre elas, o autor indica: (1.) a mobilização de conhecimentos fonéticos e, socorrendo-se de Goodman (1997), acrescenta (2.) o conhecimento semântico, (3) o conhecimento sintático e (4) o conhecimento grafo-fonético. De acordo com este autor, com o domínio e uso simultâneos de tais aspetos numa determinada língua, a leitura pode ser fluente, produtiva e conduzir ao desenvolvimento da mestria linguística (GIBBONS, 2002, p. 77-79). Igualmente, acentuando o papel do conhecimento prévio, o autor argumenta que a habilidade de leitura na LM ou, neste caso, na L2, é fundamental para a aprendizagem da leitura numa outra língua, concretamente a LE (p. 82).

O domínio de combinações grafo-fonológicas é, portanto, pertinente na aprendizagem da leitura. Nos primeiros momentos da aprendizagem da leitura em língua não materna, os aprendentes têm o desafio de treinar a leitura numa língua cujos paradigmas grafo-fonológicos, para além de serem diferentes dos das línguas que já dominam, eles não os conhecem. Assim, o professor de LE, antes de pedir a 
leitura dos alunos, faz uma que serve de modelo e inclusive, sempre que oportuno, faz o respetivo esclarecimento de ordem articulatória das combinações dos grafemas. Neste âmbito, o processamento fonológico joga um papel fulcral no exercício de leitura (IDEGUCHI, 2008).

Para Ideguchi, o processamento fonológico é bastante importante na leitura em ortografias diferentes e, por isso, é preciso, na aprendizagem da LE, considerar a relação entre o processamento fonológico e a aprendizagem de outras ortografias. O processamento fonológico na leitura implica, na verdade, a capacidade de identificar e nomear unidades linguísticas. Tudo isto implica o desenvolvimento do novo (grafemas, sílabas, etc.) através de experiências de leitura na língua conhecida, na perspetiva behaviourista.

Em conformidade com Medina (2003), os textos linguísticos são de vital importância na aprendizagem de uma LE. Os mesmos permitem simultaneamente o desenvolvimentos das habilidades de expressão, audição, escrita e leitura (p. 148155). É indubitável, certamente, que para poder desenvolver tais habilidades a partir de textos, é indispensável o exercício de leitura, quer na sala quer no contexto sociofamiliar. Debruçando-se sobre a importância da leitura no desenvolvimento da competência de LE, Sivolela (2005) advoga que nos últimos dias as atenções estão voltadas à atividade de leitura ativa, a qual torna o aluno menos dependente do professor, interagindo com o texto e desenvolvendo a língua (p. 20). Na verdade, os aspetos lexicais e fonológicos são deveras importantes para o desenvolvimento da habilidade de leitura que leve consequentemente à mestria linguística.

A questão dos aspetos fonéticos em LE e particularmente em português foi estudada por Mateus (s/d), num projeto que se intitulava diversidade linguística na escola portuguesa. Este estudo foi efetuado no contexto português, onde basicamente na sociedade e na escola se comunica em português e, com certeza, se oferece um determinado tipo de input linguístico em português, diferente do input que os alunos de PLE fora do mundo lusófono recebem. Resumidamente, no que tange aos aspetos fonéticos, Mateus revela que os alunos aprendentes de PLE em Portugal apresentam dificuldades relativas à pronúncia dos sons representados pelos grafemas $\langle\mathrm{r}\rangle,\langle 1\rangle$, $\langle\mathrm{h}\rangle,\langle\mathrm{rr}\rangle,\langle\mathrm{p}\rangle,\langle\mathrm{t}\rangle,\langle\mathrm{d}\rangle,\langle\mathrm{g}\rangle$, entre outros, como resultado das características das LMs (Guzerate, Ucraniano, crioulo de Cabo-Verde e mandarim) dos alunos. No entanto, a pronúncia desviante daqueles grafemas não pode considerada uma dificuldade generalizada, uma vez que o conhecimento linguístico prévio dos 
aprendentes de PLE, o qual condiciona a ocorrência dos desvios em causa, não é homogênio. Ademais, no que tange às oclusivas, o erro consiste no desvozeamento das vozeadas.

A partir da leitura de autores como Mateus (s/d), Espiga (2001), Alcântara (2001) e Fernandes (2001) sobre a dinâmica na aquisição de uma LE, entende-se que há muitos aspetos de índole fonética e fonológica que sobressaem. Em Mateus (s/d) sublinha-se a dificuldade dos aprendentes na aquisição e uso das oclusivas e líquidas; em Espiga (2001), o qual faz as suas análises enquadrando-as no contexto da construção da interlíngua na sala de LE (p. 264), considera-se significativa a presença da LM na aprendizagem do espanhol língua estrangeira por falantes de português. Neste contexto, Espiga sublinha que as diferenças de carácter fonético e fonológico entre o português e espanhol se fazem sentir na aprendizagem da LE (p. 268-270) envolvendo igualmente algumas consoantes oclusivas e líquidas.

Fernandes, por seu turno, relata a ocorrência frequente do fenômeno de epêntese - processo de adição de um fonema ou sílaba numa determinada palavra - na aquisição do inglês língua estrangeira por falantes de português, desenvolvendo-se desse modo a estrutura silábica (FERNANDES, 2001, p. 235-257). Esta conjuntura toda que se desenha no âmbito da fonética e fonologia na aprendizagem de uma LE leva a questionar sobre o tipo e as causas de fenômenos fonéticos que ocorrem na aquisição de PLE e, particularmente, no exercício de leitura que, como já se revelou, joga um papel preponderante na aprendizagem da língua, por falantes de um perfil linguístico particular: falantes de shona e inglês língua segunda.

\section{METODOLOGIA}

Atualmente, a importância da aprendizagem das LEs é cada vez mais crescente e significativa, por motivos de satisfação pessoal, profissionais e até mesmo socioeconômicos. Parece, hoje em dia, muito plausível a máxima de Johann Wolfgang von Goethe de que «Quem não sabe línguas estrangeiras não sabe nada da própria língua». É que o conhecimento de uma outra língua é fundamental para o conhecimento do outro e este, a chave para o autoconhecimento (cf. Como aprender línguas, 2010, p. 9). É igualmente importante o ato de leitura neste contexto (FREIRE, 1981e MEDINA, 2003) e isto remete à necessidade de encontrar estratégias para 
perceber os aspetos que caracterizam a leitura em PLE e o seu impacto em contextos específicos.

Um estudo na área de aprendizagem e uso de PLE, bem como de qualquer LE, implica por um lado a observação, a coleta e a análise de dados e produção de relatório. Implica ainda a descrição e interpretação de fenômenos fonéticos observáveis no uso de PLE por falantes de shona e inglês. Nesta perspetiva, é imprescindível o recurso ao método qualitativo de investigação científica (GÜNTHER, 2006, p. 201-209). Depois de verificar a existência de dificuldades explicáveis no âmbito da construção da interlíngua dos aprendentes zimbabweanos de PLE na Universidade do Zimbabwe e a necessidade de identificar e particularizar os fenômenos e suas causas, procedeu-se à coleta de dados. Esta atividade consistiu na gravação das leituras dos alunos no momento letivo de consolidação de uma aula de leitura, para uma posterior transcrição, descrição e análise sob o ponto de vista fonético, em contraste com as realizações no PE, norma oficialmente ensinada.

Por outro lado, o mesmo estudo implica a quantificação e classificação de dados, o que remete ao método quantitativo de investigação científica (DALFOVO, LANA E SILVEIRA, 2008). Desta feita, os dados transcritos e descritos são dispostos em gráficos indicadores das tendências fonéticas na leitura de determinados segmentos silábicos em PLE. A identificação de possíveis causas é feita através da análise comparativa das pronúncias de segmentos idênticos nas línguas de domínio dos aprendentes. Efetivamente, o recurso a um só método revela-se inadequado numa pesquisa desta natureza, havendo portanto a necessidade da combinação de abordagens, levando ao uso do método misto (TRÉZ, 2012).

A identificação do nível de variação dos aspetos em estudos consiste na diferença entre as realizações acertadas e as desviantes da pronúncia das mesmas unidades segmentais das palavras. Não são apresentados, portanto, dados de palavras em que, de forma geral, os alunos não apresentam dificuldades na leitura. Os dados a analisar são de 29 alunos do segundo ano dos seus cursos de bacharelato em diversas áreas que aprendem PLE na Universidade do Zimbabwe, com idades compreendidas entre os 19 e 30 anos. Tais alunos tinham o contacto com o português apenas no contexto escolar dado que o inglês e o shona são as suas línguas de comunicação socioprofissional. Portanto, nenhum deles tinha tido contacto prévio com a língua portuguesa, fora do contexto do ensino superior em que já somavam 180 horas correspondentes a três semestres de aprendizagem de PLE. 


\section{APRESENTAÇÃO DOS DADOS}

Os dados em estudo neste trabalho são referentes à realização fonética de certas consoantes do português que, por sinal, são de realização difícil para os falantes de shona e de inglês, como também o são para os falantes e aprendentes de outras línguas. Trata-se neste caso concreto das consoantes oclusivas $\langle\mathrm{t}\rangle,\langle\mathrm{k}\rangle \mathrm{e}\langle\mathrm{p}\rangle$, da nasal bilabial <m> em posição de coda - depois da vogal nuclear dentro de uma sílaba - da líquida $\langle\mathrm{lh}\rangle$ e do ditongo nasal <ão>, como se pode verificar na transcrição no quadro a seguir:

Tabela de transcrição fonética

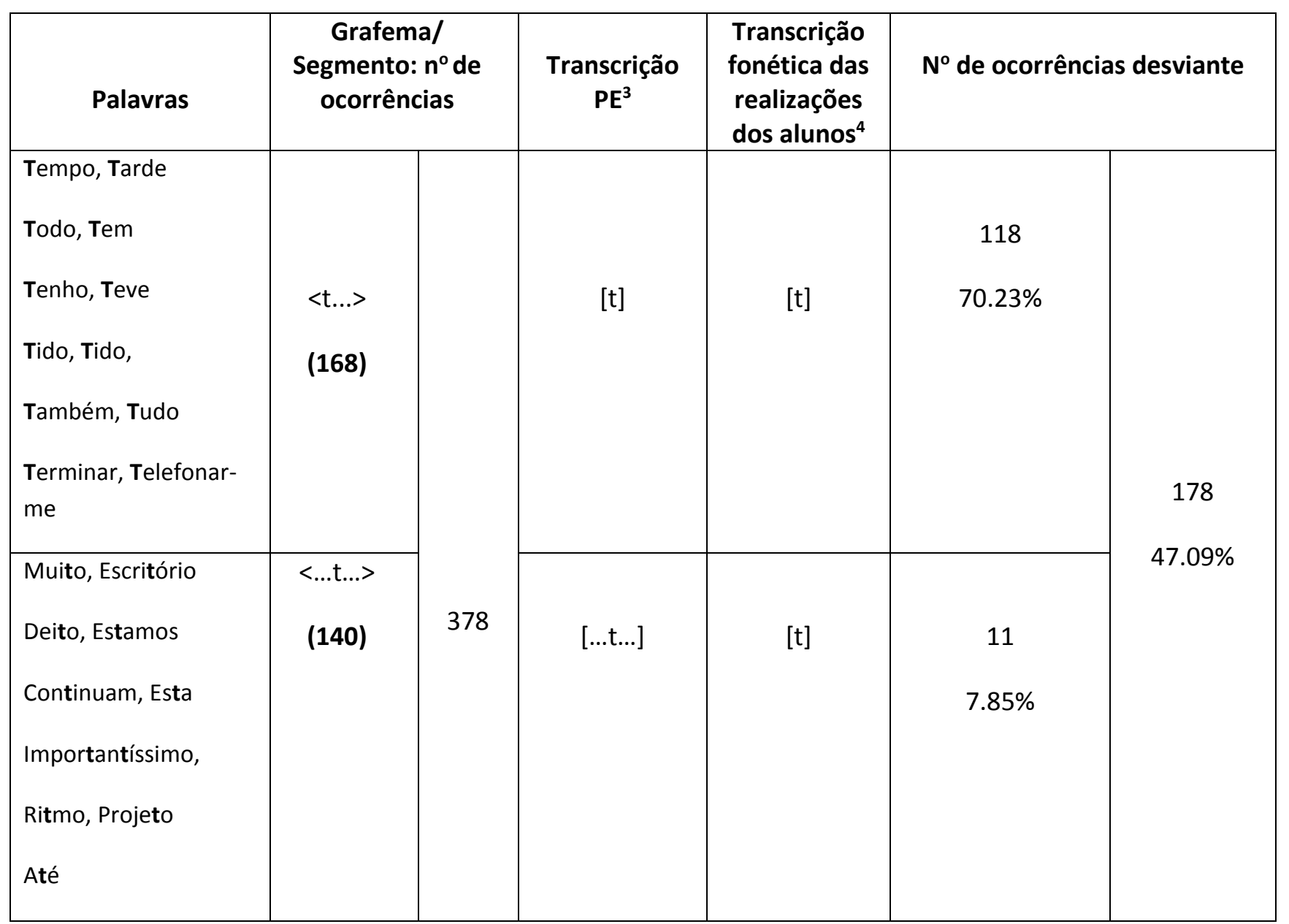

${ }^{3}$ Aqui se apresenta a transcrição convecionada para o português.

${ }^{4}$ Transcrição baseada no alfabeto fonético internacional. 
REVISTA X, Curitiba, volume 12, n.2,p.289-305,2017

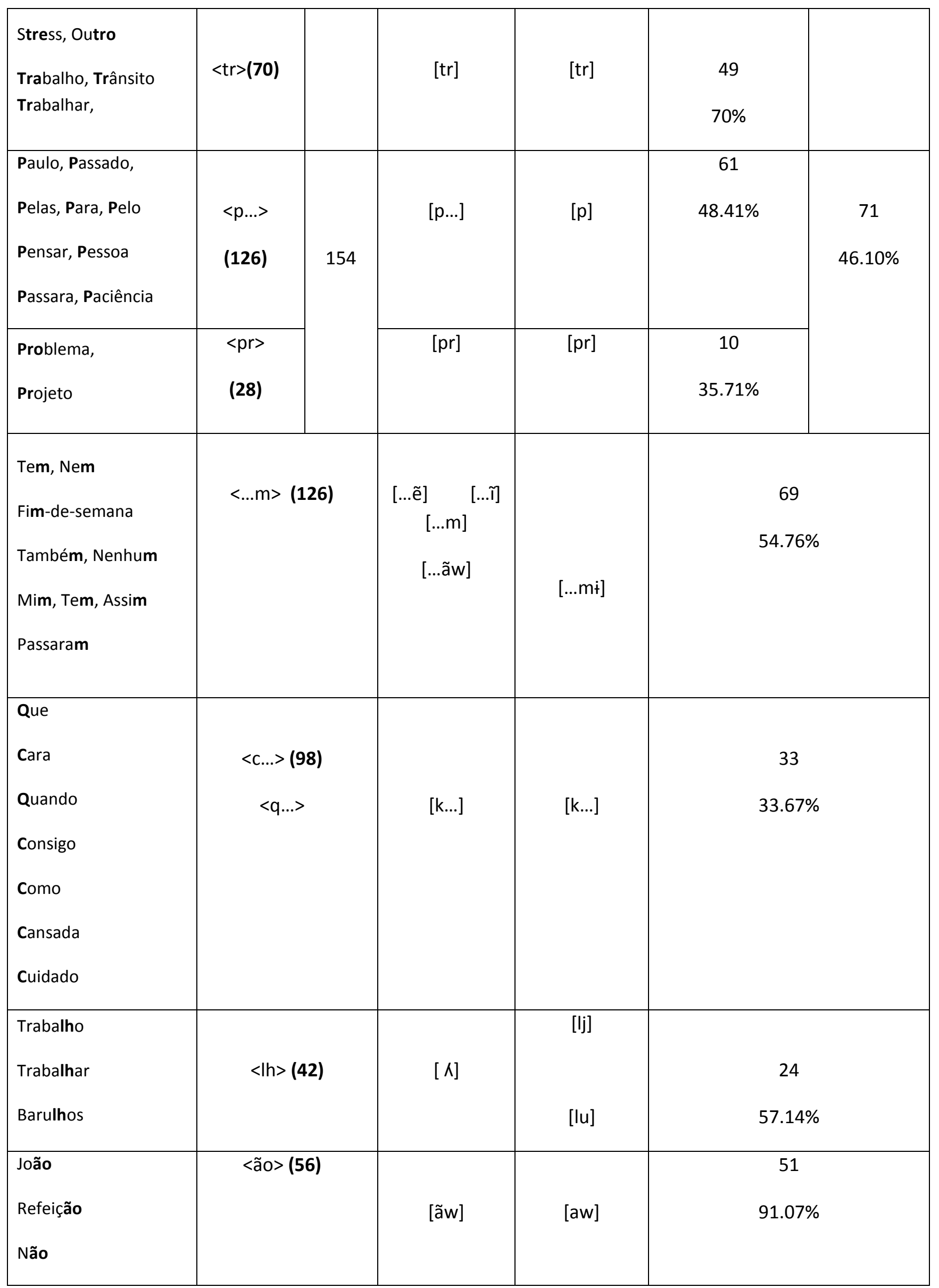


O quadro acima, referente às realizações fonética das consoantes oclusivas $[\mathrm{k}]$, [p] e [t]; da nasal bilabial $[\mathrm{m}]$; da líquida $[K]$ e do ditongo nasal [ãw], revela quatro fenômenos linguísticos que interessam destacar, por um lado, pela sua especificidade considerando o contexto em que tem lugar o ensino de PLE e, por outro, por não coincidir com os outros aspetos revelados através de estudos semelhantes envolvendo aprendentes com outro perfil linguístico realizados por vários autores podendo indicar-se Mateus (s/d), Espiga (2001), Gonçalves (2010) (esta última que revela a tendência de uso exclusivo de vogais abertas no português moçambicano, etc.).

Fica claro, entretanto, que os falantes de shona e inglês tendem a atribuir o traço [+ aspirado] às consoantes oclusivas do português $\langle\mathrm{c}\rangle,\langle\mathrm{q}\rangle,\langle\mathrm{t}\rangle \mathrm{e}\langle\mathrm{p}\rangle$. Estas três consoantes podem, numa determinada unidade lexical, aparecer na posição inicial da palavra como parte da primeira sílaba; na posição mediana, mas nunca na posição final. As três podem ser combinadas com a vibrante $\langle\mathrm{r}\rangle$, resultando num som intermitente. Os dados gerais revelam 69\% das realizações prescritas no PE, valor claramente superior aos $31 \%$ referentes às realizações desviantes. Esta situação é resultante da diminuição do desvio quando aquelas consoantes se encontram na posição mediana, como se pode observar com a consoante $\langle\mathrm{t}\rangle$ no Gráfico I, não espelhando, por isso, da melhor maneira a situação em estudo.

\section{Gráfico I}

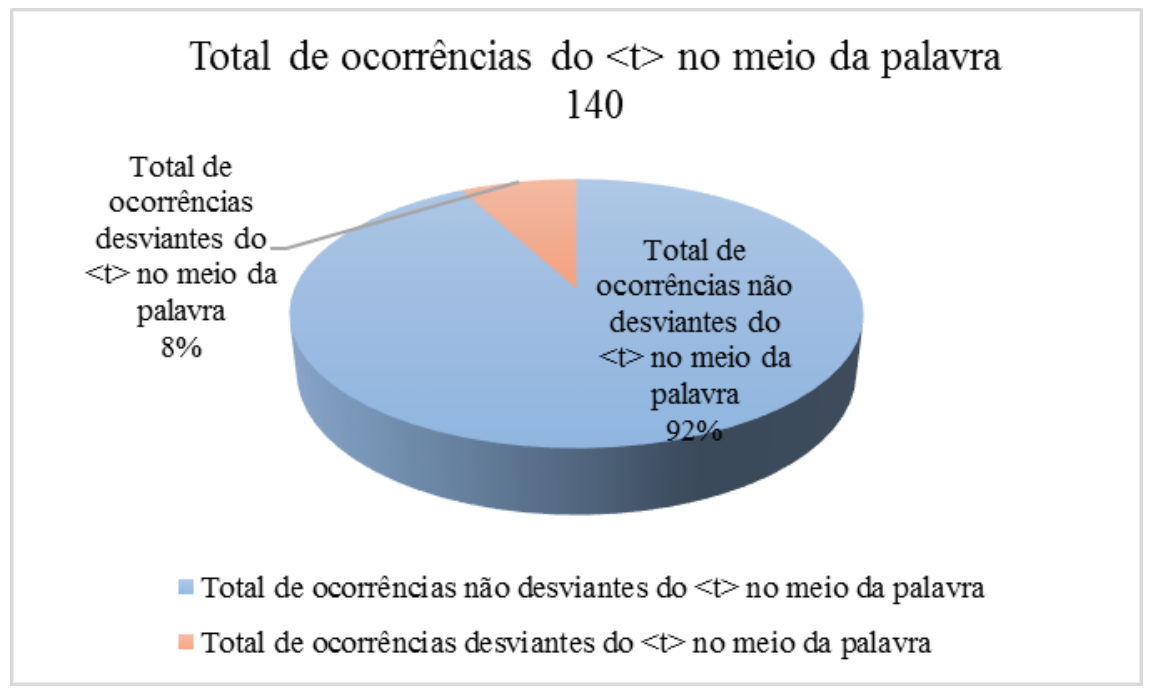


A aspiração é mais frequente quando as oclusivas $\langle t\rangle$ e $\langle p\rangle$ têm de aparecer na posição inicial respetivamente com cerca de $70 \%$ e $48 \%$. São igualmente aspiradas as consoantes $\langle t r\rangle$ e $\langle p r\rangle$ independentemente da sua posição atingindo, respetivamente, os 70\% e 36\% (vd. Grafico II) Entretanto, a consoante <c $>$ e $\langle q\rangle$ são relativamente menos aspirada (34\%) em relação às outras oclusivas em análise.

\section{Gráfico II}

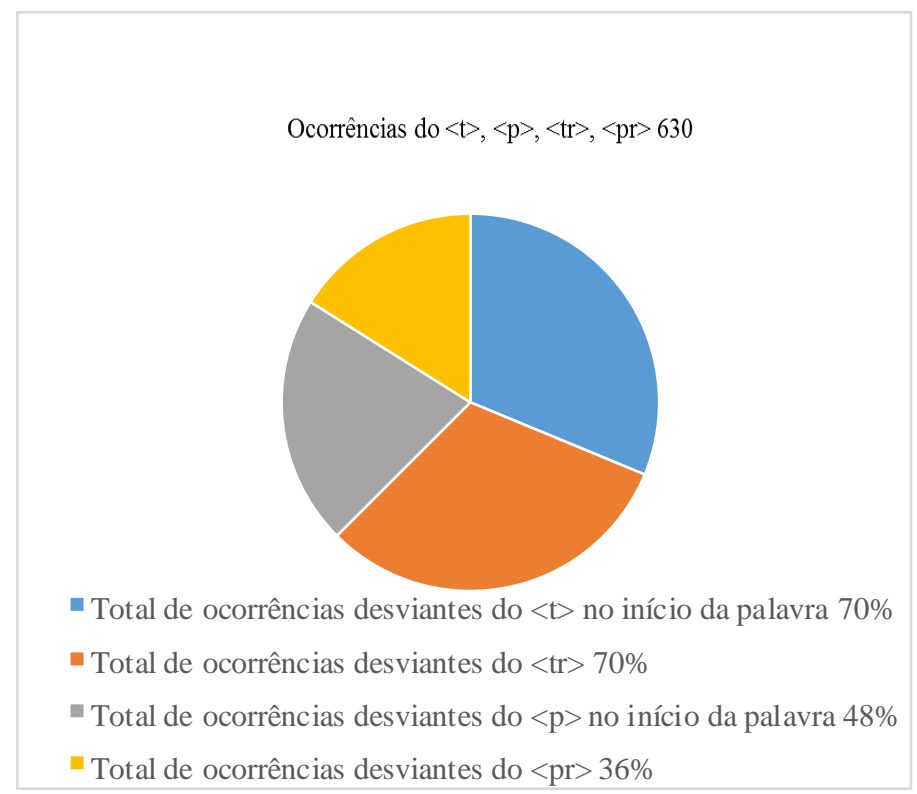

O segundo fenômeno que vem à tona através dos dados em análise é a tendência para a realização da epêntese junto da consoante nasal bilabial <m> na posição final da palavra. Em português esta consoante pode aparecer no final da palavra desempenhando funções morfossintáticas. De acordo com os dados, os aprendentes e falantes de PLE, falantes de shona e inglês, acrescentam a vogal fechada $<\dot{i}>$ na leitura da nasal $<\mathrm{m}>$ final ou na sua expressão oral. Esta tendência representa cerca de $55 \%$ das realizações fonéticas do grafema em causa. Atente-se no Gráfico III. 


\section{Gráfico III}

Total de ocorrências do $<\mathrm{m}>[\mathrm{m}]$ no final da palavra 126

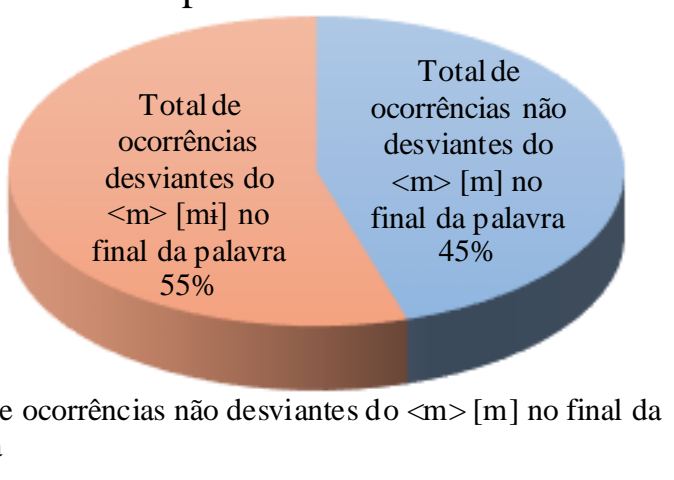

Total de ocorrências não desviantes do $\langle\mathrm{m}>[\mathrm{m}]$ no final da palavra

Em português, as consoantes $<\mathrm{lh}>\mathrm{e}<\mathrm{l}>$ são todas líquidas (ANDRADE E VIANA, 1996, p. 139). Todavia, no que tange à sua realização, verifica-se, tal como acontece em muitos casos, a substituição da líquida palatal $[K]$ pela líquida alveolar [1]. Esta tendência perfaz 57\% (Gráfico IV). Finalmente, no que respeita ao ditongo nasal [ãw], quando colocado na posição final da palavra, a tendência dos falantes em causa é para a sua desnasalização $(91 \%)$, isto é, é transformado num ditongo oral (Gráfico V).

\section{Gráfico IV}

Total de ocorrências do $<\mathrm{lh}>[K] 98$

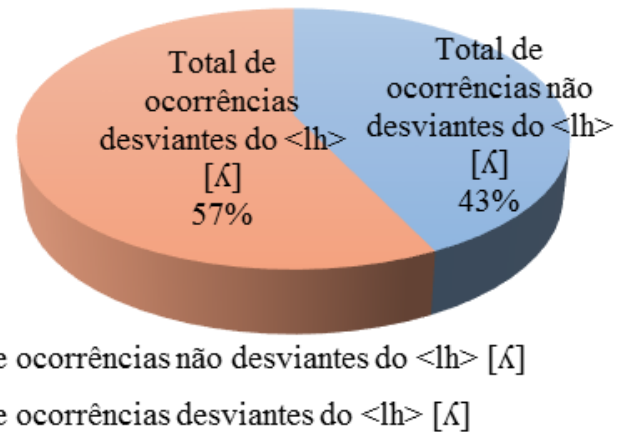




\section{Gráfico IV}

\section{Total de ocorrências do <ão $>$ [ãw] 56}

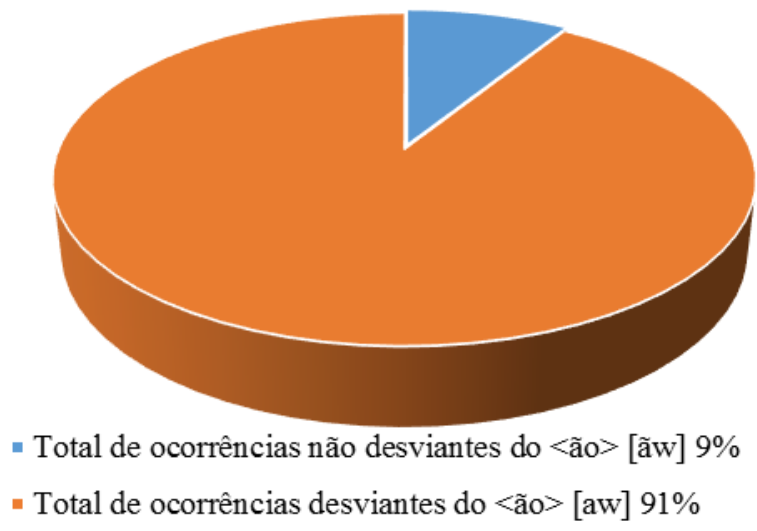

\section{DISCUSSÃO DOS RESULTADOS}

Não sendo necessariamente aspetos que comprometam o uso do português, os dados revelados com este estudo têm um impacto considerável na inteligibilidade da leitura em voz alta em PLE. Ademais, os mesmo devem ser considerados no contexto da dinâmica a que se sujeita e envolve o português, língua que se tem, nos últimos momentos, revelado não só dos portugueses, angolanos, moçambicanos, brasileiros etc. mas também de qualquer um que por prazer, motivos profissionais ou sociais queira aprendê-la. Os aspetos ora encontrados devem, por um lado, ser interpretados no âmbito da construção da interlíngua dos novos falantes de português com características particulares. Por outro, devem ser interpretados na perspetiva de Carneiro (1991) sobre a flexibilidade e capacidade de adaptação do português em diferentes contextos em que entra em contacto com outros sistemas, dando lugar à variação diastrática e diatópica.

Estes aspetos que não devem desmerecer a atenção dos profissionais de ensino de PLE representam uma fase necessária para que, com a ação educativa, os aprendentes possam desenvolver competências na nova língua. A aspiração dos fones [t], [p], [tr] e [pr] (vd. Supra Gráfico II) encontra as suas bases nos sistemas fonéticos do inglês e do shona já desenvolvidos pelos alunos. A transcrição fonética de palavras 
como time [thajmi], person [phersonì], transport [thrãsporti] e proud [phrawdi] do inglês (para informação adicional sobre a fonética do inglês cf. Forel e Puskás (1986, p. 12-14)) e tatenda [thathenda] e pinda [phĩda] do shona (cf. consoantes do shona em Fortune (1980, p. 6-8) e Doke e Litt (2005, p. 16-21)), desvenda a manutenção do traço aspirado daquelas consoantes para o português.

O contacto entre shona e inglês e português na aprendizagem desta última é um dado ineludível. Em shona, não se prevê a terminação de uma palavra por uma consoante tal como a nasal bilabial $\langle\mathrm{m}\rangle$, isto é, todas as palavras terminam por vogal (cf. Fortune, 1980, p. 11-21 e Doke e Litt, 2005, p. 42-50). Portanto, por um lado, pode se considerar, neste caso, a influência da escrita na leitura (spelling pronunciation) e, por outro, este fato pode explicar a epêntese diante da consoante $<\mathrm{m}>$ final reportada através dos dados de leitura dos aprendentes de PLE analisados. Em inglês também, apesar de se prever a ocorrência do $\langle\mathrm{m}\rangle$ no final de palavras como em curriculum [kaRikjulami] ou a sua ocorrência na palavra sem vogal como em cirumstances [sekamistãsis], a sua pronúncia, em todas as posições, revela a presença da vogal fechada $\langle\dot{i}>$ sempre acrescentada na leitura dos alunos em estudo, o que também explica o fenômeno de epêntese.

$\mathrm{Na}$ mesma perspetiva, a ausência da líquida palatal $[K]$ em shona e inglês propicia a ocorrência do desvio fonético na leitura e na fala em português, levando os alunos a recorrer à líquida alveolar apenas presente no inglês. Igualmente, nas duas línguas dos alunos não se prevê a ocorrência de ditongos nasais condicionando sobremaneira a pronúncia dos ditongos nasais português com traços de orais.

Portanto, os falantes de shona e inglês, como resultado da influência destas línguas, exibem aspetos fonéticos particulares se comparados com os outros com perfis linguísticos diferentes cujos estudos foram efetuados noutros contextos. Diferentemente dos resultados apresentados por Mateus (s/d), por exemplo, em que sublinha a confusão entre a líquida velar [1] e a líquida vibrante $[r]$, entre $[r]$ e $[R]$ e o desvozeamento das consoantes $[\mathrm{d}],[\mathrm{g}]$ e [v] (oclusivas e fricativas), os alunos em estudo apresentam outros fenômenos: a aspiração das oclusivas $[\mathrm{p}]$, $[\mathrm{t}]$ em diferentes posições na palavra e a não realização de $[K]$. É ainda relativamente particular a este público o fenômeno de epêntese junto da bilabial nasal final [m]. Sendo comum a estes e aqueles a realização oralizada do ditongo <ãw>. 


\section{CONCLUSÃO}

O processo de leitura é deveras importante na aquisição de uma LE e, neste caso concreto, de PLE, uma vez que a leitura cria possibilidades para o desenvolvimento de muitas habilidades linguísticas e promove a independência do aluno em relação ao professor, devendo, por isso, merecer tratamento cauteloso, na leitura em voz alta, na sala de PLE por todos os agentes.

No processo de leitura bem como na oralidade dos falantes de shona e de inglês encontram-se quatro tendências reveladoras da construção das interlínguas dos alunos, resultantes do contacto entre as sua línguas e o português. Trata-se de quatro fenômenos a saber: (1) a aspiração dos fones [t], [p] e [k], em diferentes posições e combinações; (2) a colocação sistemática de uma vogal [i] junto à consoante <m> na posição final da palavra, consoante que é sujeita ao apagamento pelos falantes competentes, enquanto o grupo em estudo mantém-na e acrescenta-lhe a vogal. Verifica-se também, (3) a não realização da consoante $[K]$ do português dando lugar à lateral alveolar [1], e (4) a oralização do ditongo nasal [ãw].

Estes aspetos todos apelam para uma atividade mais cuidadosa e deliberadamente dedicada à resolução de desvios de pronúncia na leitura para que o aluno se beneficie de todas as vantagens da boa pronúncia das palavras na sua aventura de aprendizagem do PLE.

\section{REFERÊNCIAS}

ALCÂNTARA, C. C. O processo de aquisição de LE: o caso das vogais frontais arredondadas do Francês. In: HERNANDORENA, C. L. M. (Org.). Aquisição de Língua Materna e de Língua Estrangeira. Aspetcos fonético. Pelotas: EDUCAT, 2001. pp. 211-234.

BLEY-VROMAN, R. The Logical Problem of Foreign Language Learning. Linguistic Analysis, v. 20, n. 1-2, pp. 2-49, 1990. Disponível em:

$<$ https://www.researchgate.net/profile/Robert_BleyVroman/publication/240412239 The _Logical_Problem_of_Foreign_Language_Learn ing/links/55671a8008aeccd777378100/The-Logical-Problem-of-Foreign-LanguageLearning.pdf> Acesso em 13.10.2016.

BOCK, A., FURTADO, O. e TEIXEIRA, M. Psicologias - Uma introdução ao estudo de Psicologia. São Paulo: Saraiva, 1999 ${ }^{13}$, pp. 492. 
CARNEIRO, R. Educação intercultural, 1991. Disponível em: $<$ https://cld.pt/dl/download/ 348350ae-1731-412fb0c1bc293d1e60b2/A\%20Educa\%C3\%A7\%C3\%A3o\%20

Intercultural_Roberto\%20Carneiro\%20.pdf >. Acesso em 13.10.2016.

DALFOVO, M. S., LANA, R. A. e SILVEIRA, A. Métodos quantitativos e qualitativos: um resgate teórico. Revista Interdisciplinar Científica Aplicada, Blumenau, v.2, n.4, pp. 01-13, 2008, 13, Sem II. 2008.

DOKE, C. M. e LITT, M. A. The unification of the shona dialects. Oslo: Allex Project, 2005.

DUARTE, I. Da repetição de modelos à intervenção educativa cientificamente fundamentada. Atas do $V$ congresso internacional de didática da língua e da literatura. Almedina, 2000. Pp. $47-61$.

ESPIGA, J. Interferências e interlínguas no aprendizado de espanhol por falantes nativos de Português: aspetos de fonologia In: HERNANDORENA, C. L. M. (Org.), Aquisição de língua materna e de língua estrangeira. Aspectos fonéticos. Pelotas: EDUCAT, 2001. Pp. 261-276.

FERNANDES, P. R. C. A epêntese nas formas oral e escrita na interfonologia Português/Inglês. In: HERNANDORENA, C. L. M. (Org.), Aquisição de Língua Materna e de Língua Estrangeira. Aspectos fonéticos. Pelotas: EDUCAT, 2001. Pp. 235-266.

FESTAS, M. I. F., MARTINS, C. S. P. e LEITÃO, A. S. G. Avaliação da compreensão escrita e da leitura de palavras na PAL-PORT (bateria de avaliação psicolinguística das afasias e de outras perturbações da linguagem para a população portuguesa). Revista Educação: Temas e Problemas, v.4, n.2 (n ${ }^{\circ}$ especial sobre leitura), pp. 1-19,2007.

FOREL C. \& PUSKÁS, G. Phonetics and phonology: Reader for first year English linguistics. University of Geneva, 1986. 64p. Disponível em: <https://www.unioldenburg.de/fileadmin/user_upload/anglistik/personen/cornelia.hamann/Phonology.p df>. Acesso em 13.102016.

FORTUNE, G. Shona grammatical construction. Harare: Mercury Press, 1985.

FREIRE, P. Importância do ato de ler em três artigos que se complementam. São Paulo: Editora Cortez e Editora Autores associados (coleção polémicas do nosso tempo), 1981.

GIBBONS, P. Reading in a second language. Scaffolding language, scaffolding Learning, 2002. Pp. 77-101. Disponível em <http://www.heinemann.com> Acesso em 13.10.2016.

GÜNTHER, H. Pesquisa qualitativa versus pesquisa quantitativa: esta é a questão?. Psicologia: Teoria e Pesquisa. , v. 22, n. 2, pp. 201-210, 2006. Disponível em: <http://www.scielo.br/pdf/ptp/v22n2/a10v22n2.pdf >. Acesso em 13.10.2016. 
IDEGUCHI, S. Phonological processing and reading in different orthographies. Polyglossia, v.14, pp. 77-82, 2008. Disponível em: <http://www.apu.ac.jp/rcaps/ uploads/fckeditor/publications/polyglossia/Polyglossia_V14_Ideguchi.pdf.> Acesso em: 13.10.2016.

KRASHEN, S. D. Second language acquisition and second language learning. Pergamon Press Inc, 1981.

MEDINA, B. L. The role of text linguistics in the foreign language class. Encuentro Revista de investigación e innovación en la clase de idiomas, 2003. Pp. 148-158.

MATEUS,M.H.M. (s/d). Breve caracterização fonética de sons que apresentam problemas na pronúncia de alunos estrangeiros. Projeto Diversidade Linguística na Escola Portuguesa. Disponível em: $<$ https://giel2014.files.wordpress.com/2013/12/diversidade-lingc3bcc3adstica-nasescolas.pdf $>$. Acesso em 13.10.2016.

NGUNGA, A. Interferências de línguas moçambicanas em português falado em Moçambique. Revista científica da Universidade Eduardo Mondlane, série: Letra e Ciência Sociais. pp. 7- 20. Disponível em:

$<$ http://www.revistacientifica.uem.mz/index.php/seriec/article/view/15/28> Acesso em 12-12-2012.

SIVOLELLA, M. F. F. A leitura no processo de ensino aprendizagem de língua estrangeira no ensino médio. R. Janeiro: Universidade Cândido Mendes (Projeto a vez do mestre), 2005.

TRÉZ, T. A. Caracterizando o método misto de pesquisa na educação: Um continuum entre a abordagem qualitativa e quantitativa. Atas de pesquisa em educação $P P G E / M E$, v. 7, n.4, pp. 1132-1157, 2012. Disponível em: $\langle$ http://proxy.furb.br/ojs/index.php/atosdepesquisa/article/view/1132/2235>. Acesso em 13.102016.

UNIÃO Europeia. Como aprender línguas, 2005. Disponível em:<http://europa.eu.>Acesso em 13.10.2013. 